\title{
Efeito da inclusão de óleo de linhaça nas rações sobre o desempenho e os parâmetros ósseos de frangos de corte ${ }^{1}$
}

\author{
Alice Eiko Murakami ${ }^{2}$, Elis Regina de Moraes Garcia ${ }^{3}$, Elias Nunes Martins ${ }^{2}$, Ivan Moreira ${ }^{2}$, \\ Claudio Scapinello ${ }^{2}$, Andréia Fróes Galuci de Oliveira ${ }^{3}$
}

1 Projeto financiado pelo CNPq.

2 Departamento de Zootecnia da Universidade Estadual de Maringá/UEM, Maringá, PR.

${ }^{3}$ Curso de Pós-graduação em Zootecnia da Universidade Estadual de Maringá/UEM, Maringá, PR.

RESUMO - O objetivo neste trabalho foi avaliar o desempenho e os parâmetros ósseos de frangos de corte alimentados com rações contendo diferentes níveis de óleo de linhaça no período de 1 a 42 dias de idade. Nas fases inicial e de crescimento ( 1 a 21 dias e 22 a 42 dias, respectivamente), foi adotado delineamento inteiramente casualizado com 4 níveis de óleo de linhaça $(2,0 ; 3,5 ; 5,0$ ou $6,5 \%), 6$ repetições e 50 aves/unidade experimental. Os níveis de óleo de linhaça tiveram efeito linear crescente sobre o diâmetro e o peso absoluto da tíbia, mas não influenciaram o peso do fêmur. Os dados revelaram interação idade e nível de óleo de linhaça para o índice de Seedor, comprovando que os efeitos positivos e negativos dos maiores níveis de óleo de linhaça observados para o fêmur e a tíbia, respectivamente, aumentaram no final da fase de crescimento. Os parâmetros de crescimento e qualidade do fêmur e da tíbia apresentaram comportamento cúbico, decorrente da idade. Os níveis de óleo de linhaça e a idade tiveram efeito quadrático sobre o peso das cinzas do fêmur. A concentração de cinzas foi positivamente influenciada pelos níveis de óleo de linhaça nas rações, contudo, os melhores resultados foram evidenciados a partir dos 28 dias. A resistência óssea não foi influenciada pela ingestão de óleo de linhaça, mas sofreu efeito cúbico da idade. Verificou-se interação significativa idade $\times$ nível de óleo de linhaça para a densidade mineral óssea, e que os melhores efeitos do óleo ocorrem na fase inicial de criação das aves. Rações contendo $6,5 \%$ de óleo de linhaça são benéficas para o crescimento e a mineralização dos ossos longos de frangos de corte.

Palavras-chave: cinzas, densidade mineral, fêmur, índice de Seedor, resistência à quebra, tíbia

\section{Effect of linseed oil inclusion in diets on the performance and bone parameters of broiler chickens}

\begin{abstract}
This study aimed to evaluate the performance and bone parameters of broiler chickens fed on diets with different linseed oil (LO) levels from 1 to 42 days of age. At the initial and growing phases (1 to 21 days and 22 to 42 days of age, respectively) a completely randomized design was used with four linseed oil levels $(2.0,3.5,5.0$ or $6.5 \%)$, six replicates and 50 birds per experimental unit. The birds were fed diets with different linseed oil levels $(2.0 ; 3.5 ; 5.0$ and $6.5 \%)$. A linear effect of linseed oil was observed on tibia absolute diameter and weight but the femur was not influenced by linseed oil inclusion in the diet. Data revealed significant interaction between age and linseed oil levels for the Seedor index, demonstrating that the positive and negative effects of the highest linseed oil levels observed for femur and tibia, respectively, increased at the end of the growth phase. The femur and tibia growth and quality parameters presented cubic performance in function of age. The inclusion of linseed oil and age showed a quadratic effect on the femur ash weight. The ash concentration was positively influenced by the levels of linseed oil in the diets but the best results were shown after 28 days. The bone strength was not influenced by the different linseed oil levels, but showed cubic performance in function of age. However, there was significant age $\times$ linseed oil level interaction for bone mineral density, so that the best results with linseed oil addition were observed at the initial rearing stage of the birds. It was concluded that diets with $6.5 \%$ linseed oil are beneficial to growth and mineralization of long bones in broiler chickens.
\end{abstract}

Key Words: ash, femur, mineral density, Seedor index, strength, tibia

\section{Introdução}

A seleção genética dos frangos de corte para o crescimento muscular tem resultado em desbalanço no desenvolvimento de vários tecidos, causando aumento na demanda de nutrientes para integridade do esqueleto (Williams et al., 2000) e o aparecimento de falhas esqueléticas associadas ao rápido crescimento longitudinal

Este artigo foi recebido em 1/2/2007 e aprovado em 14/10/2008. 
e diametral dos ossos longos em frangos modernos (Williams et al., 2004).

Visando ao balanceamento energético adequado para atender à alta exigência nutricional de frangos de corte, o uso de óleos vegetais ou gordura animal nas rações tem sido uma prática constante.

De acordo com Liu \& Denbow (2001), os ácidos graxos poliinsaturados (AGPI) são estrutural e fisiologicamente importantes para a mineralização e a regulação da modelagem óssea, pois servem de substratos para síntese de substâncias, chamadas eicosanóides, que estariam envolvidas na regulação local do crescimento e desenvolvimento do osso (Watkins, 2002).

O ácido linoléico é convertido a ácido araquidônico no fígado das aves e estocado nos fosfolipídios das membranas dos osteoblastos e condrócitos. Fatores sistêmicos (hormônio da paratireóide - PTH) e localizados (citocinas e fatores de crescimento) podem estimular a liberação do ácido araquidônico, que serve de substrato para a síntese da PGE $_{2}$ (prostaglandina E2) (Watkins, 2003). Tanto a formação quanto a reabsorção óssea são influenciadas pela $\mathrm{PGE}_{2}$ e esse efeito sobre o osso pode depender de sua concentração, ou seja, altas concentrações inibem a formação da matriz óssea, enquanto baixas concentrações podem estimular a formação do osso (Liu \& Denbow, 2001).

Entre os óleos vegetais utilizados na alimentação animal, o de linhaça se caracteriza pela alta concentração de ácido linolênico, um AGPI da série ômega 3 (Kratzer \& Vohra, 2005), que compete com o ácido linoléico pelas enzimas hepáticas envolvidas nos processos de insaturação e alongamento da cadeia dos ácidos graxos, reduzindo a produção de ácido araquidônico e a síntese de $\mathrm{PGE}_{2}$. Dessa forma, a ingestão de maiores concentrações de óleos ricos em AGPI da série ômega 3 pode reduzir a incorporação de ácido araquidônico nas membranas e diminuir a capacidade de síntese de eicosanóides provenientes desse ácido graxo (Calder, 1998).

Com base nessas considerações, o objetivo neste trabalho foi avaliar o efeito da inclusão de óleo de linhaça nas rações sobre o desempenho, os parâmetros de crescimento e a qualidade óssea de frangos de corte no período de 1 a 42 dias de idade.

\section{Material e Métodos}

O experimento foi realizado na Fazenda Experimental de Iguatemi da Universidade Estadual de Maringá - UEM. Foram utilizados 1.200 pintos de 1 dia de idade (peso médio de $45 \mathrm{~g}$ ), machos, da linhagem Cobb-Vantress ${ }^{\circledR}$. As aves foram alojadas em galpão convencional dividido em boxes de $6,3 \mathrm{~m}^{2}$ com cobertura de telha francesa e lanternin, piso de concreto e paredes laterais de alvenaria com tela de arame até o telhado, providas de cortinas laterais. Foi utilizada cama do tipo maravalha sobre o piso.

$\mathrm{Na}$ fase inicial, foram utilizados comedouros do tipo bandeja e bebedouros do tipo copo de pressão até os 5 dias de idade, que foram substituídos gradativamente por comedouros tubulares e bebedouros automáticos do tipo pendular. Em cada boxe, foram utilizados um círculo de proteção e uma campânula como fonte de aquecimento para os pintinhos. Água e ração foram fornecidas à vontade em um programa de alimentação dividido em duas fases: a inicial de 1 a 21 dias de idade, e a de crescimento/acabamento, de 22 a 43 dias de idade.

Foi adotado um programa contínuo de luz durante os primeiros dez dias e o restante do período experimental com 23 horas de luz/dia. As temperaturas máxima e mínima observadas no interior do galpão foram $29,9 \pm 0,6^{\circ} \mathrm{C}$ e $22,6 \pm 0,6^{\circ} \mathrm{C}$, respectivamente, com umidade relativa média de $48,2 \pm 2,7 \%$.

As aves foram alimentadas com rações formuladas com diferentes níveis de óleo de linhaça, constituindo um delineamento inteiramente casualizado com quatro tratamentos $(2,0 ; 3,5 ; 5,0$ ou $6,5 \%$ de óleo de linhaça), seis repetições e 50 aves/unidade experimental.

As rações experimentais foram formuladas de modo a atender às exigências nutricionais das aves nas fases: inicial (1-21 dias de idade) e de crescimento/acabamento (22-43 dias de idade), de acordo com recomendações de Rostagno et al. (2005), de forma a serem isoenergéticas, isoaminoacídicas, isocálcicas e isofosfóricas (Tabelas 1e 2).

Foram avaliados o desempenho zootécnico (ganho de peso, consumo de ração e conversão alimentar) e os parâmetros relativos aos ossos: comprimento, diâmetro, peso, índice de Seedor, densitometria óptica radiográfica, resistência e concentração de minerais (cinzas). Para avaliação do desempenho, as rações e as aves foram pesadas no início do experimento, aos 7, 14, 21 e aos 43 dias de idade.

Os parâmetros ósseos foram avaliados após o sacrifício das aves, por meio de atordoamento seguido de sangria (aprovado pelo Comitê de Ética Animal - Registro No 069/ 2003). Foram coletados os fêmures e as tíbias esquerdas de duas aves/repetição (peso médio $\pm 5 \%$ ) aos 7, 14, 21, 28, 35 e 42 dias de idade, que foram mantidos congelados $\left(-18^{\circ} \mathrm{C}\right)$ até o início das análises. Após o descongelamento dos ossos, foram retirados os tecidos envolventes (tecido muscular aderido) com auxílio de tesouras e pinças. Os ossos frescos foram pesados em balança analítica ( $\pm 0,0001 \mathrm{~g}$ ) e o comprimento e o diâmetro (na porção média 
Tabela 1 - Composições das rações experimentais fornecidas na fase de 1 a 21 dias de idade

\begin{tabular}{|c|c|c|c|c|}
\hline \multirow[t]{2}{*}{ Ingrediente } & \multicolumn{4}{|c|}{ Nível de óleo de linhaça (\%) } \\
\hline & 2,0 & 3,5 & 5,0 & 6,5 \\
\hline Milho, grão & 62,20 & 57,62 & 53,14 & 48,66 \\
\hline Farelo de soja, $45 \%$ & 31,74 & 33,07 & 33,92 & 34,76 \\
\hline Fosfato bicálcico & 1,88 & 1,89 & 1,90 & 1,91 \\
\hline Calcário & 1,04 & 1,02 & 1,01 & 1,00 \\
\hline Óleo & 2,00 & 3,50 & 5,00 & 6,50 \\
\hline Sal comum & 0,43 & 0,43 & 0,43 & 0,43 \\
\hline Dl-metionina, $98 \%$ & 0,27 & 0,27 & 0,28 & 0,28 \\
\hline L-lisina $\mathrm{HCl}, 78 \%$ & 0,28 & 0,26 & 0,24 & 0,22 \\
\hline Inerte & 0,00 & 1,78 & 3,92 & 6,08 \\
\hline Suplemento mineral ${ }^{1}$ & 0,05 & 0,05 & 0,05 & 0,05 \\
\hline Suplemento vitamínico ${ }^{2}$ & 0,10 & 0,10 & 0,10 & 0,10 \\
\hline Butil-hidroxi-tolueno & 0,01 & 0,01 & 0,01 & 0,01 \\
\hline Total & 100,00 & 100,00 & 100,00 & 100,00 \\
\hline \multicolumn{5}{|l|}{ Valores calculados } \\
\hline Proteína bruta (\%) & 20,00 & 20,00 & 20,00 & 20,00 \\
\hline $\begin{array}{l}\text { Energia metabolizável } \\
\text { aparente }(\mathrm{kcal} / \mathrm{kg})\end{array}$ & 3.000 & 3.000 & 3.000 & 3.000 \\
\hline Metionina + Cistina $(\%)$ & 0,897 & 0,897 & 0,897 & 0,897 \\
\hline Lisina $(\%)$ & 1,263 & 1,263 & 1,263 & 1,263 \\
\hline Cálcio $(\%)$ & 0,960 & 0,960 & 0,960 & 0,960 \\
\hline Fósforo disponível (\%) & 0,450 & 0,450 & 0,450 & 0,450 \\
\hline Extrato etéreo $(\%)$ & 4,380 & 5,720 & 7,060 & 8,390 \\
\hline Sódio $(\%)$ & 0,222 & 0,222 & 0,222 & 0,222 \\
\hline
\end{tabular}

${ }^{1}$ Suplemento mineral ${ }^{\circledR}$ (Conteúdo por kg de premix): ferro - $100.000 \mathrm{mg}$; cobre $16.000 \mathrm{mg}$; iodo - $2.400 \mathrm{mg}$; zinco - $100.000 \mathrm{mg}$; manganês - $140.000 \mathrm{mg}$; selênio - $400 \mathrm{mg}$; veículo q.s.p. - $1.000 \mathrm{~g}$.

2 Suplemento vitamínico inicial ${ }^{\circledR}$ (Conteúdo por kg de premix): vit. A - 7.000.000 UI; vit. D3 - 2.200.000 UI; vit. E - $11.000 \mathrm{mg}$; vit. K3 - $1.600 \mathrm{mg}$; vit. B1 - $2.000 \mathrm{mg}$; vit. B2 - $5.000 \mathrm{mg}$; vit. B12 - $12.000 \mu \mathrm{g}$; vit. B6 - $3.000 \mathrm{mg}$; niacina $-35.000 \mathrm{mg}$; ácido pantotênico - $13.000 \mathrm{mg}$; ácido fólico - $800 \mathrm{mg}$; antioxidante $-100.000 \mathrm{mg}$; veículo q.s.p. - $1.000 \mathrm{~g}$.

do osso) foram medidos usando paquímetro eletrônico digital (capacidade de 0 a $150 \mathrm{~mm}$ e precisão de 0,01 $\mathrm{mm}$ ).

Dividindo-se o peso do osso $(\mathrm{mg})$ pelo seu comprimento (mm), foi calculado o Índice de Seedor (Seedor et al., 1991), utilizado como indicativo da densidade óssea: quanto maior o Índice de Seedor, maior a densidade da peça óssea e vice-versa.

A densitometria óssea radiográfica (densidade mineral óssea) foi determinada apenas nos fêmures esquerdos. Inicialmente, as peças ósseas limpas (sem tecidos envolventes) foram colocadas sob o filme fotográfico (marca Kodak Insight ${ }^{\circledR}$, size 2 IP-21, tipo periapical), todas na posição antero-posterior, e então radiografadas utilizando-se aparelho de raio-X, marca DABI ${ }^{\circledR}$, modelo Atlanti-Spectro 70x, calibrado, com distância foco-filme de $45 \mathrm{~cm}$, ajustado para $70 \mathrm{kVp}, 8 \mathrm{mAs}$ e tempo de exposição de 0,3 segundo. Esses valores de tensão, corrente e tempo de exposição foram considerados ideais após análises prévias. As radiografias foram processadas em reveladora automática, marca Avi Techiques Inc. ${ }^{\circledR}$, modelo Peri-Pro maintenace, utilizando-se tempo de processamento de
Tabela 2 - Composições das rações experimentais fornecidas na fase de 22 a 43 dias de idade

\begin{tabular}{|c|c|c|c|c|}
\hline \multirow[t]{2}{*}{ Ingrediente } & \multicolumn{4}{|c|}{ Nível de óleo de linhaça (\%) } \\
\hline & 2,0 & 3,5 & 5,0 & 6,5 \\
\hline Milho, grão & 68,43 & 64,40 & 59,91 & 55,43 \\
\hline Farelo de soja, $45 \%$ & 25,80 & 27,40 & 28,25 & 29,09 \\
\hline Fosfato bicálcico & 1,66 & 1,68 & 1,69 & 1,69 \\
\hline Calcário & 0,99 & 0,97 & 0,96 & 0,95 \\
\hline Óleo & 2,00 & 3,50 & 5,00 & 6,50 \\
\hline Sal comum & 0,37 & 0,37 & 0,37 & 0,37 \\
\hline D1-metionina, $98 \%$ & 0,25 & 0,25 & 0,25 & 0,26 \\
\hline L-lisina $\mathrm{HCl}, 78 \%$ & 0,34 & 0,30 & 0,28 & 0,27 \\
\hline Inerte & 0,00 & 0,97 & 3,13 & 5,28 \\
\hline Suplemento mineral ${ }^{1}$ & 0,05 & 0,05 & 0,05 & 0,05 \\
\hline Suplemento vitamínico ${ }^{2}$ & 0,10 & 0,10 & 0,10 & 0,10 \\
\hline Butil-hidroxi-tolueno & 0,01 & 0,01 & 0,01 & 0,01 \\
\hline Total & 100,00 & 100,00 & 100,00 & 100,00 \\
\hline \multicolumn{5}{|l|}{ Valores calculados } \\
\hline Proteína bruta (\%) & 18,00 & 18,00 & 18,00 & 18,00 \\
\hline $\begin{array}{l}\text { Energia metabolizável } \\
\text { aparente }(\mathrm{kcal} / \mathrm{kg})\end{array}$ & 3.100 & 3.100 & 3.100 & 3.100 \\
\hline Metionina + Cistina $(\%)$ & 0,825 & 0,825 & 0,825 & 0,825 \\
\hline Lisina $(\%)$ & 1,156 & 1,156 & 1,156 & 1,156 \\
\hline Cálcio (\%) & 0,874 & 0,874 & 0,874 & 0,874 \\
\hline Fósforo disponível(\%) & 0,406 & 0,406 & 0,406 & 0,406 \\
\hline Extrato etéreo (\%) & 4,550 & 5,910 & 7,250 & 8,580 \\
\hline Sódio $(\%)$ & 0,192 & 0,192 & 0,192 & 0,192 \\
\hline
\end{tabular}

${ }^{1}$ Suplemento mineral ${ }^{\circledR}$ (conteúdo por kg de premix): ferro - $100.000 \mathrm{mg}$; cobre $16.000 \mathrm{mg}$; iodo $2.400 \mathrm{mg}$; zinco $100.000 \mathrm{mg}$; manganês $140.000 \mathrm{mg}$; selênio $400 \mathrm{mg}$; veículo q.s.p. - $1.000 \mathrm{~g}$.

${ }^{2}$ Suplemento vitamínico crescimento ${ }^{\circledR}$ (conteúdo por kg de premix): vit. A $6.000 .000 \mathrm{UI}$; vit. D3 - $2.000 .000 \mathrm{UI}$; vit.E - $10.000 \mathrm{mg}$; vit. K3 - $1.600 \mathrm{mg}$; vit. B1 - $1.400 \mathrm{mg}$; vit. B2 - $4.000 \mathrm{mg}$; vit. B12 - $10.000 \mu \mathrm{g}$; vit. B6 - $2.000 \mathrm{mg}$; niacina - $30.000 \mathrm{mg}$; ácido pantotênico - $11.000 \mathrm{mg}$; ácido fólico $-600 \mathrm{mg}$; antioxidante $-100.000 \mathrm{mg}$; veículo q.s.p. $-1.000 \mathrm{~g}$.

6 minutos para revelação e fixação. Sequencialmente, as radiografias foram digitalizadas em scanner, marca HPScan Jet, modelo 4 CTT, com tampa de transparência acoplada, utilizando-se o software HP Deskscan, com resolução de 2400 DPI (Dots Per Inch = pontos por polegada) e gravadas em arquivo com extensão JPG.

A leitura das radiografias, para determinação da densidade das peças ósseas, foi realizada utilizando-se a ferramenta histograma do software Adobe Photoshop 8.0. Como referencial radiográfico, nas tomadas radiográficas, utilizou-se escada de alumínio (penetrômetro de alumínio) de 10 degraus com $1 \mathrm{~mm}$ de espessura entre um degrau e outro. As leituras densitométricas foram realizadas em cinco pontos na região central da imagem radiográfica e em cada degrau da escada de alumínio.

Os dados obtidos em valores de cinza foram convertidos em valores relativos à espessura da escada de alumínio (mmAL), indicando a densidade mineral óssea. Quanto maior o valor obtido, maior a radiopaticidade e a densidade.

$\mathrm{Na}$ análise da resistência óssea, os fêmures esquerdos foram previamente preparados, colocados em água fervente 
e, após a retirada do tecido muscular aderido, foram mergulhados em éter por 24 horas para desengorduramento e posteriormente secos em estufa de ventilação forçada a $55^{\circ} \mathrm{C}$ por 72 horas. As análises de resistência foram realizadas em uma máquina universal de ensaios mecânicos, marca EMIC $^{\circledR}$ - modelo DL3000, e os dados foram coletados por um computador diretamente acoplado à máquina, com uso do Programa Computacional Tesc ${ }^{\circledR}$, e expressos em Newton (N). As peças ósseas foram posicionadas em apoios da região das epífises e ficaram sem apoio na região central. A posição escolhida foi a antero-posterior para evitar que ossos se deslocassem no momento da quebra. A força foi aplicada na região central, sempre no mesmo ponto em todos os ossos. A velocidade de descida da sonda para aplicação da força foi a mesma $(5 \mathrm{~mm} / \mathrm{s})$ para todos os ossos, de modo que a força aplicada foi mensurada no momento anterior à ruptura do osso. A carga utilizada foi de $200 \mathrm{kgf}$ (_ 1974 N) para todas as amostras, entretanto, as distâncias entre os apoios foram de 20, 25, 35, 40, 45 e $55 \mathrm{~mm}$ para os ossos de 7, 14, 21, 28, 35 e 42 dias, respectivamente.

Após o ensaio para determinação da resistência óssea, os fêmures esquerdos foram secos (estufa de ventilação forçada), triturados, pesados em balança analítica $(0,0001 \mathrm{~g})$, secos em estufa a $105^{\circ} \mathrm{C}$ por 12 horas, pesados após resfriamento e calcinados em mufla a $600^{\circ} \mathrm{C}$, por 24 horas, para obtenção das cinzas.

As análises estatísticas dos parâmetros ósseos (comprimento, diâmetro, peso, Índice de Seedor, densitometria óptica radiográfica e resistência óssea) foram realizadas por meio da análise de superfície de resposta, considerando o nível de óleo de linhaça e a idade variáveis independentes. O método de modelos lineares generalizados (Nelder \& Wedderburn, 1972) foi utilizado admitindo-se distribuição gama com função de ligação recíproca. Para as características de desempenho e a concentração de minerais, foi admitida a distribuição normal. Os dados foram submetidos a análise de variância e, posteriormente, a análises de regressão polinomial considerando os níveis de óleo de linhaça dentro de cada idade. As análises estatísticas foram realizadas com auxílio do Programa Computacional SAS ${ }^{\circledR}$ (SAS, 2001).

\section{Resultados e Discussão}

Com a inclusão crescente de óleo de linhaça nas rações, o consumo de ração teve aumento quadrático $(\mathrm{P}<0,05)$ no período de 1 a 7 dias, com ponto de máximo estimado aos 4,6\% de óleo (Tabela 3). Segundo Freeman (1984), aves jovens apresentam menor capacidade de produção de lipase pancreática e deficiência na produção de bile. Com isso, a digestão e a absorção das gorduras
Tabela 3 - Equações de regressão obtidas para as características de desempenho de frangos de corte alimentados com rações com diferentes níveis de óleo de linhaça no período de 1 a 43 dias de idade

\begin{tabular}{|c|c|c|c|}
\hline Idade & Equação & & \\
\hline & Consumo de ração (g/ave) & $\mathrm{R}^{2}$ & $\mathrm{P} \S$ \\
\hline 1 a 7 dias & $\hat{Y}=127,42+7,64 X-0,83 X^{2}$ & 0,97 & $* *$ \\
\hline 1 a 14 dias & $\mathrm{NS}^{\dagger}$ & - & - \\
\hline 1 a 21 dias & NS & - & - \\
\hline \multirow[t]{2}{*}{1 a 43 dias } & NS & - & - \\
\hline & Ganho de peso $(\mathrm{g})$ & $\mathrm{R}^{2}$ & $\mathrm{P} \S$ \\
\hline 1 a 7 dias & $\hat{Y}=122,87+1,77 X$ & 0,90 & $* *$ \\
\hline 1 a 14 dias & $\hat{\mathrm{Y}}=390,34+6,47 \mathrm{X}$ & 0,99 & $* *$ \\
\hline 1 a 21 dias & $\hat{\mathrm{Y}}=802,15+10,26 \mathrm{X}$ & 0,97 & $*$ \\
\hline \multirow[t]{2}{*}{1 a 43 dias } & NS & - & - \\
\hline & Conversão alimentar (g/g) & $\mathrm{R}^{2}$ & $\mathrm{P} \S$ \\
\hline 1 a 7 dias & $\hat{Y}=1,14-0,0103 X$ & 0,87 & $* *$ \\
\hline 1 a 14 dias & $\hat{\mathrm{Y}}=1,28-0,014 \mathrm{X}$ & 0,96 & $* * *$ \\
\hline 1 a 21 dias & $\hat{\mathrm{Y}}=1,40-0,011 \mathrm{X}$ & 0,95 & $* *$ \\
\hline 1 a 43 dias & $\hat{\mathrm{Y}}=1,82-0,018 \mathrm{X}$ & 0,92 & $*$ \\
\hline
\end{tabular}

$\dagger$ NS = não-significativo.

$\S \mathrm{P}=$ nível de probabilidade pelo teste de $\mathrm{F}$

$* \mathrm{P}<0,05 ; * * \mathrm{P}<0,01 ; * * * \mathrm{P}<0,001$

são menores, o que estimula o consumo para atender às necessidades energéticas. Contudo, esse quadro se inverte com o avanço da idade (Noy \& Sklan, 1995). O mesmo resultado não foi observado $(\mathrm{P}>0,05)$ nos períodos de 1 a 14 , 1 a 21 e 1 a 43 dias de idade.

Os resultados obtidos diferem dos encontrados por Pucci et al. (2003), que observaram que a inclusão de até $7,5 \%$ de óleo de soja nas rações aumentou linearmente o consumo pelas aves nos períodos de 1 a 21 e 22 a 42 dias de idade. Por outro lado, Tabeeidian et al. (2005) verificaram menor consumo de ração pelos frangos de corte alimentados com 7,5\% de óleo de soja, no período de 7 aos 21 dias de idade.

Constatou-se aumento linear $(\mathrm{P}<0,05)$ no ganho de peso, com subsequente melhoria na conversão alimentar, no período inicial de criação, resultado que está acordo com os encontrados por Dutra Jr. et al. (1991) e Pucci et al. (2003), que avaliaram o efeito da adição de níveis crescentes de óleo de abatedouro avícola e soja às rações, respectivamente. Essa melhoria no ganho de peso e na conversão alimentar podem ser atribuídos ao efeito extracalórico das gorduras, decorrente de sua maior concentração de energia líquida (Sakomura et al., 2004), visto que a deposição de gordura na ave é mais eficiente quando se utiliza gordura proveniente da dieta, em comparação à síntese de ácidos graxos e glicerol, a partir 
de precursores da acetil coenzima A. Dessa forma, a adição de gordura na ração promove redução da síntese de ácidos graxos e, consequentemente, a ave dispõe de mais energia para os seus propósitos produtivos (Franco, 1992).

No período de 1 a 43 dias de idade, no entanto, embora o ganho de peso e o consumo de ração não tenham apresentado melhora significativa, a conversão alimentar melhorou de forma linear $(\mathrm{P}<0,05)$ com a adição de óleo às dietas, evidenciando os efeitos benéficos desse ingrediente no desempenho das aves. Os resultados diferiram parcialmente dos obtidos por Zelenka et al. (2006), que constataram melhoria no consumo de ração, no ganho de peso e na conversão alimentar de frangos de corte alimentados com rações contendo 5 e $7 \%$ de óleo de linhaça, em comparação a frangos que receberam 1 e $3 \%$ no período de 20 a 40 dias de idade. Da mesma forma, Nitsan et al. (1997) evidenciaram efeitos positivos da adição de óleo de soja nas rações sobre a conversão alimentar em frangos de corte no período de 3 a 6 semanas de idade.

$\hat{\mathrm{Y}}=\left(0,0584-0,004403 * \mathrm{I}+0,0001292 * \mathrm{I}^{2}-0,0000012984 * \mathrm{I}^{3}-0,0005 * \mathrm{~N}+0,000011 * \mathrm{I}^{*} \mathrm{~N}\right)^{-1}$ $\left(\mathrm{R}^{2}=0,99\right)$
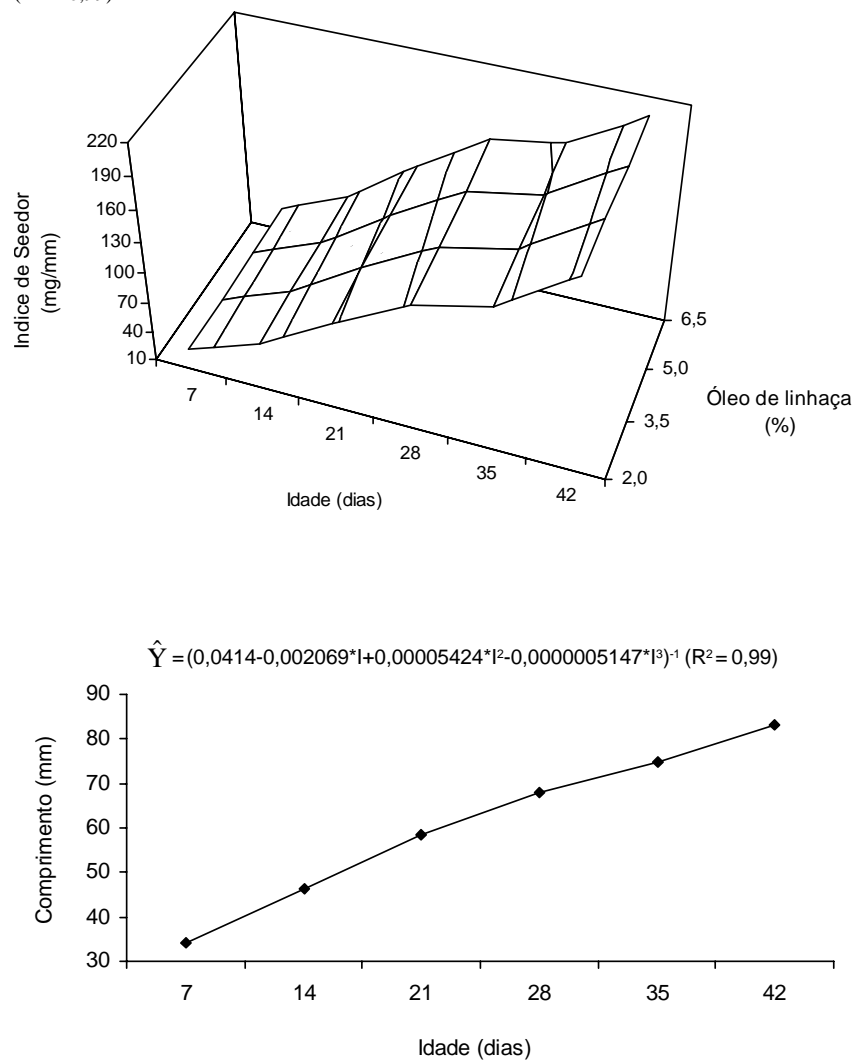

O diâmetro, o peso e o comprimento absolutos do fêmur não foram influenciados $(\mathrm{P}>0,05)$ pela inclusão de óleo de linhaça nas rações das aves (Figuras 1 e 2). Entretanto, constatou-se interação significativa $(\mathrm{P}<0,05)$ entre idade e níveis de óleo de linhaça para o peso e o diâmetro absolutos da tíbia das aves, portanto, os efeitos positivos da adição de óleo de linhaça às rações foram maiores nos períodos inicial e de crescimento. Entretanto, constatou-se interação significativa $(\mathrm{P}<0,05)$ entre idade e níveis de inclusão de óleo de linhaça sobre o peso e o diâmetro absolutos da tíbia das aves, demonstrando que os efeitos positivos da adição de óleo de linhaça às rações foram potencializados nos períodos inicial e de crescimento. Esses resultados, provavelmente, estão correlacionados com o melhor desempenho das aves alimentadas com as rações contendo os maiores níveis de óleo de linhaça. O comprimento absoluto da tíbia não foi influenciado $(\mathrm{P}<0,05)$ pela adição de óleo de linhaça às rações.

$\hat{\mathrm{Y}}=\left(0,4475-0,026975 * \mathrm{I}+0,00074059 * \mathrm{I}^{2}-0,0000070271 * \mathrm{I}^{3}\right)^{-1}\left(\mathrm{R}^{2}=0,99\right)$
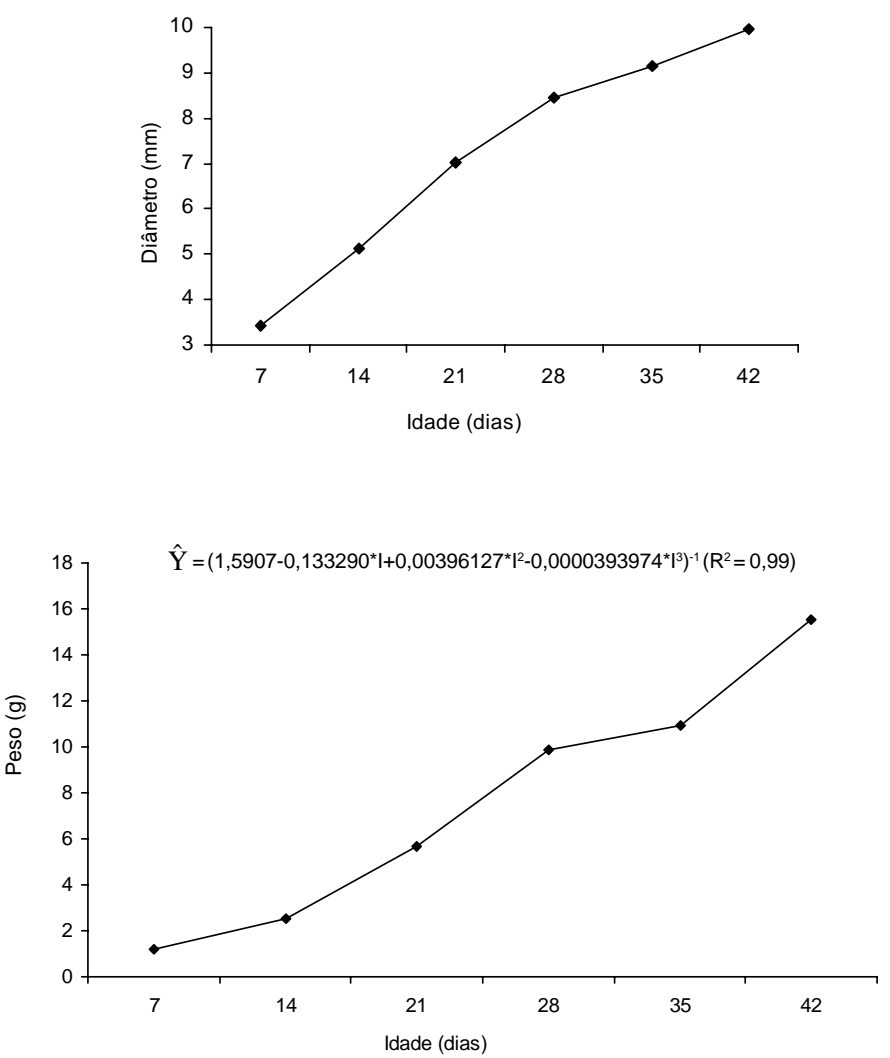

Figura 1 - Parâmetros ósseos determinados no fêmur de frangos de corte alimentados com rações com óleo de linhaça no período de 1 a 42 dias de idade.

$\mathrm{I}=$ idade; $\mathrm{N}$ = nível de óleo de linhaça. 
$\hat{\mathrm{Y}}=\left(0,0525-0,003972^{*}\left|+0,00011827^{\star}\right|^{2}-0,0000012074^{\star}||^{3}-0,0005^{\star} \mathrm{N}+0,\left.000012^{\star}\right|^{*} \mathrm{~N}\right)^{-1}$ $\left(R^{2}=0,99\right)$

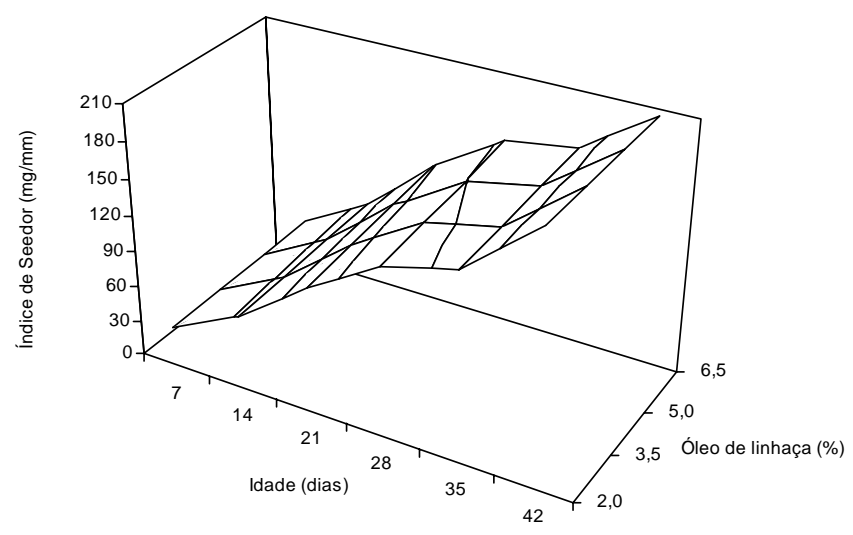

$\hat{Y}=\left(0,0319-0,001654^{\star}\left|+0,00004458^{\star}\right|^{2}-0,\left.000000437^{\star}\right|^{3}\right)^{-1}\left(R^{2}=0,99\right)$

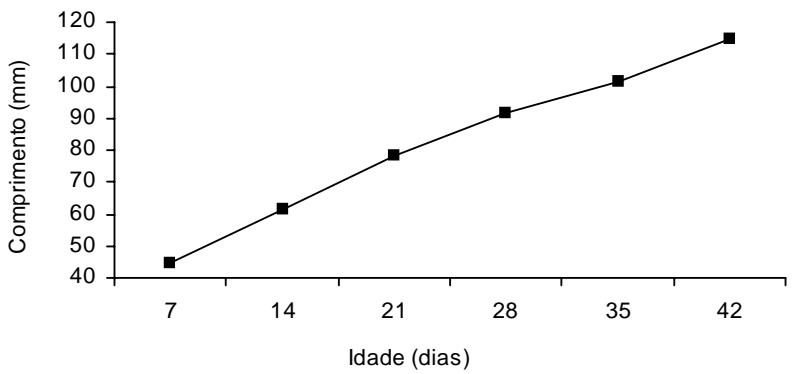

$\hat{\mathrm{Y}}=\left(0,4999-0,030366^{*}\left|+0,00084299^{\star}\right|^{2}-0,\left.00000819253^{\star}\right|^{3}-0,0048^{*} \mathrm{~N}+0,\left.000111^{*}\right|^{*} \mathrm{~N}\right)^{-1}$ $\left(R^{2}=0,99\right)$

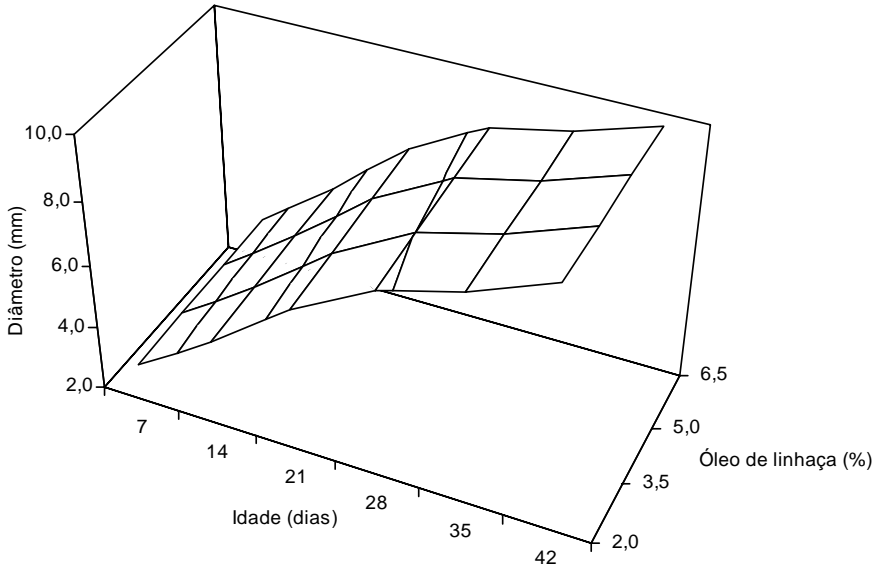

$\hat{\mathrm{Y}}=\left(1,11335-0,0068^{*} \mathrm{~N}-0,091935^{*}\left|+0,00273495^{*}\right|^{2}-0,\left.0000274582^{*}\right|^{3}+0,000166^{*} \mathrm{~N}^{*} \mid\right)^{-1}$ $\left(R^{2}=0,99\right)$

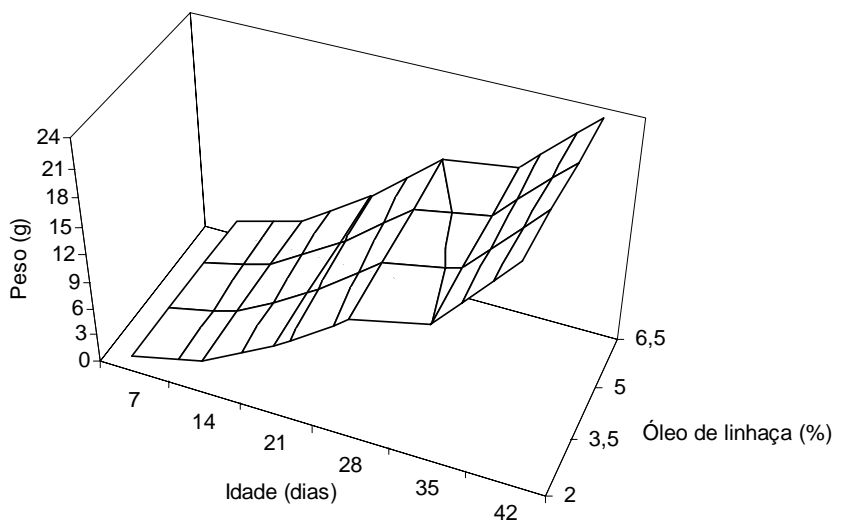

Figura 2 - Parâmetros ósseos determinados na tíbia de frangos de corte alimentados com rações contendo óleo de linhaça no período de 1 a 42 dias de idade.

I = idade; $\mathrm{N}$ = nível de óleo de linhaça.

De acordo com Williams et al. (2000), em pesquisa sobre o efeito do crescimento sobre o desenvolvimento dos ossos, os animais que crescem mais rápido, ou seja, os mais pesados, apresentam ossos mais longos, com maiores diâmetros e maiores valores de espessura da região cortical. Além disso, neste estudo, a inclusão de óleo de linhaça pode ter proporcionado maiores valores de energia líquida às aves, favorecendo o desenvolvimento dos tecidos, inclusive o tecido ósseo.

Concordando com essas observações, Leterrier \& Nys (1992) constataram aumento no comprimento e no peso (seco e úmido) da tíbia de frangos com o avanço da idade, no período de 1 a 37 dias, e verificaram que os valores obtidos para as linhagens de rápido crescimento foram superiores aos daquelas de crescimento lento.

Em contrapartida, Reddish \& Lilburn (2004) enfatizaram a existência de diferenças no desenvolvimento ósseo quando aplicada a seleção para ganho de peso entre as linhagens. Esses autores observaram que frangos de corte selecionados para maior crescimento do músculo do peito apresentaram menores valores para o comprimento, embora a espessura do fêmur e da tíbia tenham sido semelhantes à observada com 8 semanas de idade.

Segundo Rutten et al. (2002), menor carga sobre os ossos, em decorrência do menor peso vivo, pode reduzir o peso do fêmur aos 19 dias de idade e, da mesma forma, aumentar o crescimento longitudinal dos ossos, em virtude da menor pressão sobre a placa de crescimento. Do mesmo modo, Reich et al. (2004) observaram ossos mais curtos e placas de crescimento mais estreitas, ocasionados pelo aumento nas taxas de ossificação e vascularização em ossos longos de aves submetidas a maior carga de peso.

Os parâmetros de crescimento e qualidade do fêmur e da tíbia também foram influenciados pela idade e apresentaram comportamento cúbico $(\mathrm{P}<0,05)$ no período de 1 a 42 dias de idade, contrariando os encontrados por Skinner \& Waldroup (1995), Bruno et al. (2000) e Yalcin et al. (2001). 
Observou-se interação idade × nível de óleo de linhaça $(\mathrm{P}<0,05)$ para o índice de Seedor e essa interação indica que os efeitos positivos e negativos dos maiores níveis de óleo de linhaça observados para o fêmur e a tíbia, respectivamente, aumentaram no final da fase de crescimento. Esses resultados comprovam que o fêmur pode ser tão sensível às mudanças nutricionais quanto a tíbia (Moran \& Todd, 1994) e também ser avaliado em estudos sobre as características do desenvolvimento ósseo em aves (Applegate \& Lilburn, 2002).

$O$ peso das cinzas teve efeito quadrático $(\mathrm{P}<0,05)$ do nível de óleo de linhaça (ponto de máximo estimado aos $5,0 \%$ de inclusão) e da idade (ponto de máximo estimado aos 27 dias) (Figuras 3 e 4). Embora a concentração de cinzas tenha apresentado redução quadrática com o avanço da idade, constatou-se interação entre os níveis de óleo de linhaça e a idade $(\mathrm{P}<0,05)$ : na fase inicial, as aves alimentadas com as rações com os maiores níveis de óleo de linhaça apresentaram menores concentrações de cinzas ósseas, entretanto, a partir dos 28 dias, os melhores resultados quanto à mineralização do fêmur foram obtidos com os maiores níveis de óleo nas rações.

Esses resultados corroboram os encontrados por Bar et al. (2003), que concluíram que os frangos de corte aumentam o peso e reduzem a porcentagem de cinzas nos ossos com o decorrer da idade. No entanto, o efeito deletério dos maiores níveis de óleo de linhaça sobre a concentração de cinzas no fêmur durante a fase inicial pode estar relacionado à formação de sabões insolúveis entre os ácidos graxos livres e os minerais durante o processo digestório, o que reduz o teor de cinzas e a retenção de cálcio nos ossos (Andreotti et al., 2004), pois, nessa fase, há intensa taxa de formação (4 aos 18 dias de idade) e mineralização óssea (4 aos 11 dias de idade) (Williams et al., 2000).

Contudo, a superioridade na concentração de cinzas obtida no final da fase de crescimento com os maiores níveis de óleo de linhaça nas rações provavelmente foi resultado da maior disponibilidade mineral com o passar da idade, pois, em aves mais velhas, quando os sabões insolúveis são formados na porção superior do trato digestório, podem ser solubilizados ao alcançarem a porção posterior em razão das mudanças de $\mathrm{pH}$ (Leeson \& Zubair, 2006).

As ações positivas dos ácidos graxos poliinsaturados ômega 3 (ácido graxo eicosapentaenóico - EPA) sobre os ossos podem ser atribuídas à sua ação de aumentar a absorção de cálcio no intestino e melhorar a formação óssea pelo aumento na deposição de cálcio e pela redução na reabsorção óssea por meio da menor excreção urinária de cálcio (Claassen et al., 1995; Krueger \& Horrobin, 1997).
$\hat{\mathrm{Y}}=-0,4562833333+0,135557 * \mathrm{~N}-0,013537037 * \mathrm{~N}^{2}-0,03216602891 * \mathrm{I}+0,00059417511701 * \mathrm{I}^{2}$ $\left(\mathrm{R}^{2}=0,99\right)$

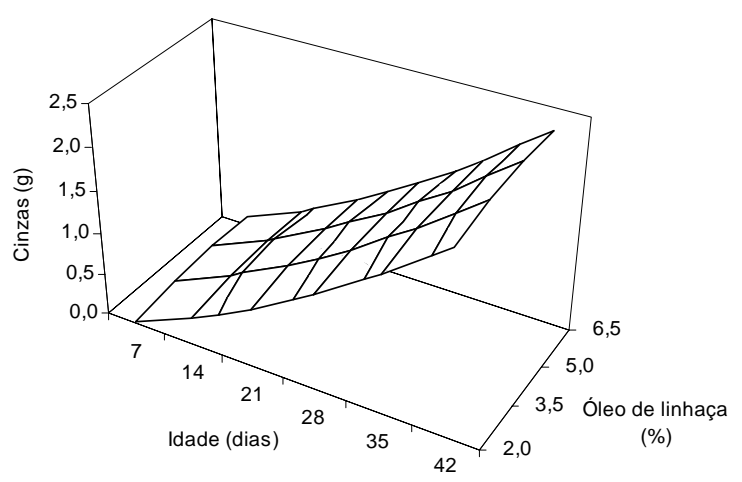

Figura 3 - Peso das cinzas (g) determinado no fêmur de frangos de corte alimentados com rações com diferentes níveis de óleo de linhaça no período de 1 a 42 dias de idade $\mathrm{I}$ = idade; $\mathrm{N}$ = nível de óleo de linhaça.

$\hat{\mathrm{Y}}=34,1562+0,30675289 * \mathrm{I}-0,01224308 * \mathrm{I}^{2}-0,7950666 * \mathrm{~N}+0,03067619 * \mathrm{I} * \mathrm{~N} ;\left(\mathrm{R}^{2}=0,99\right)$

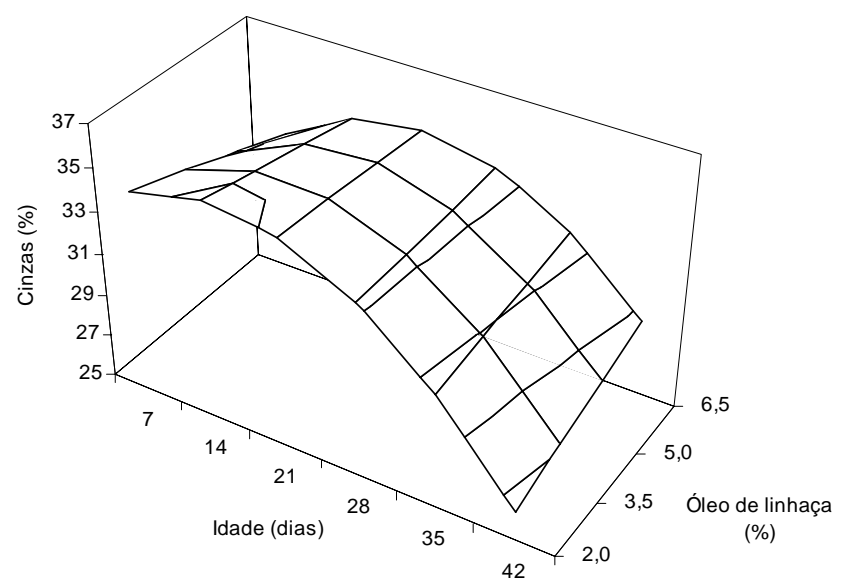

Figura 4 - Concentração de cinzas (\%) no fêmur de frangos de corte alimentados com rações com diferentes níveis de óleo de linhaça no período de 1 a 42 dias de idade.

$\mathrm{I}$ = idade; $\mathrm{N}$ = nível de óleo de linhaça.

Essas afirmativas poderiam explicar os resultados positivos em relação à mineralização do fêmur com a adição crescente de óleo de linhaça às rações, o que confirma o possível efeito dos ácidos graxos de cadeia longa da série ômega 3 sobre o desenvolvimento e a composição mineral do osso, conforme observado por Liu et al. (2003).

A resistência óssea não foi influenciada $(\mathrm{P}>0,05)$ pelo aumento no nível de óleo de linhaça nas rações, entretanto apresentou comportamento cúbico $(\mathrm{P}<0,05)$ com a idade (Figuras 5 e 6). Esses resultados diferem dos encontrados por Yalcin et al. (2001), que observaram aumento quadrático na resistência e densidade mineral óssea de frangos de corte com o avanço da idade. Contudo, Reis et al. (2005) 
relataram comportamento semelhante para a resistência à quebra da tíbia de frangos de corte avaliados aos 21, 28, 35 e 42 dias de idade.

Rath et al. (1999) demonstraram a existência de correlações positivas entre a resistência óssea e o conteúdo de cinzas, a densidade mineral, as ligações cruzadas de piridinolina e a fluorescência da matriz orgânica. Contudo, os maiores valores foram obtidos para as ligações cruzadas de piridinolina e a fluorescência da matriz, sugerindo que essa variável é altamente influenciada pela quantidade de ligações cruzadas entre as fibras de colágeno. Esses resultados evidenciam que não apenas o conteúdo mineral, mas também fatores ligados à matriz orgânica do osso, é responsável pela resistência óssea (Rath et al., 2000) (Rath et al., 2000). Segundo Oviedo-Rondón (2005), os dados

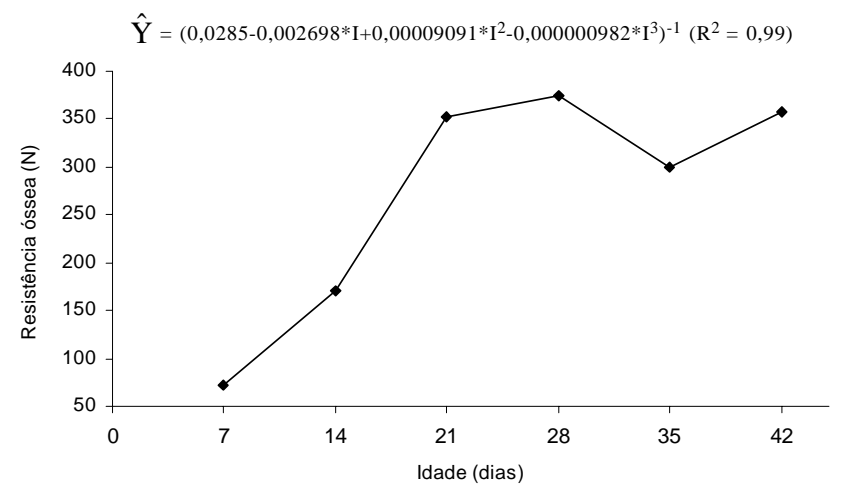

Figura 5 - Resistência óssea a quebra determinada no fêmur de frangos de corte, alimentados com rações com diferentes níveis de óleo de linhaça no período de 1 a 42 dias de idade. $\mathrm{I}$ = idade; $\mathrm{N}$ = nível de óleo de linhaça.

\section{$\hat{\mathrm{Y}}=\left(1,5192-0,1133 * \mathrm{I}+0,003642 * \mathrm{I}^{2}-0,00003909 * \mathrm{I}^{3}-0,0178 * \mathrm{~N}+0,000532 * \mathrm{~N} * \mathrm{I}\right)^{-1} ;\left(\mathrm{R}^{2}=0,99\right)$}

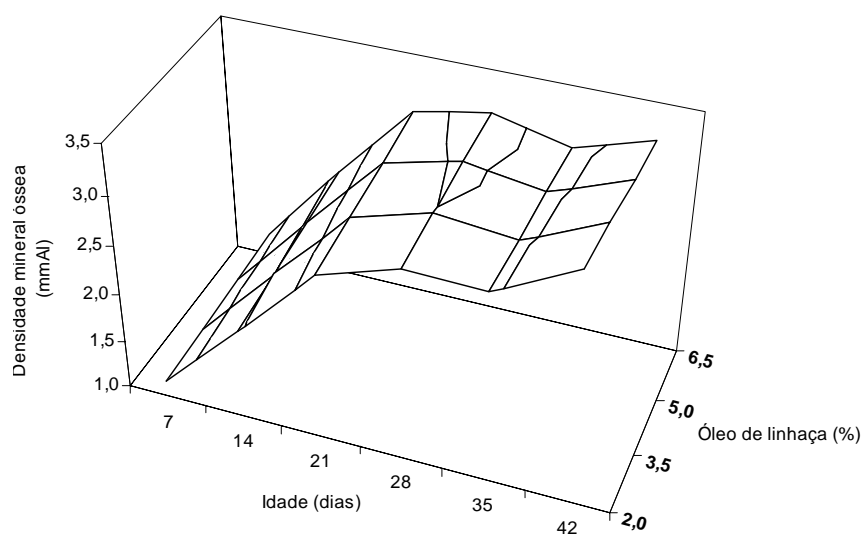

Figura 6 - Densidade mineral óssea determinada no fêmur de frangos de corte, alimentados com rações com diferentes níveis de óleo de linhaça no período de 1 a 42 dias de idade.

$\mathrm{I}=$ idade; $\mathrm{N}$ = nível de óleo de linhaça. referentes ao desenvolvimento ósseo em aves variam conforme as metodologias utilizadas nas avaliações.

Para a densidade mineral óssea, observou-se interação significativa $(\mathrm{P}<0,05)$ entre idade e níveis de óleo de linhaça, demonstrando que os efeitos positivos da adição de óleo de linhaça às rações aumentaram no período inicial de criação das aves.

Os resultados obtidos indicaram comportamento semelhante para o Índice de Seedor e o peso das cinzas, o que justifica a relação entre essas variáveis e o provável efeito do óleo de linhaça como fonte de precursores dos ácidos graxos poliinsaturados ômega 3 de cadeia longa envolvidos na mineralização e no desenvolvimento ósseo.

\section{Conclusões}

A inclusão de óleo de linhaça às rações de frangos de corte melhora o ganho de peso nas fases inicial (1 a 21 dias) e total ( 1 a 43 dias) e a conversão alimentar no período total (1 a 43 dias) de criação. Os parâmetros de crescimento e qualidade óssea da tíbia e do fêmur de frangos de corte são positivamente influenciados pelos níveis de óleo de linhaça nas rações, no entanto, a adição de óleo de linhaça na ração não afeta a resistência óssea. O fornecimento de rações contendo $6,5 \%$ de óleo de linhaça é benéfico para o crescimento e a mineralização dos ossos longos de frangos de corte.

\section{Literatura Citada}

ANDREOTTI, M.O.; JUNQUEIRA, O.M.; BARBOSA, M.J.B. et al. Tempo de trânsito intestinal, desempenho, características de carcaça e composição corporal de frangos de corte alimentados com rações isoenergéticas formuladas com diferentes níveis de óleo de soja. Revista Brasileira de Zootecnia, v.33, n.4, p.870-879, 2004.

APPLEGATE, T.J.; LILBURN, M.S. Growth of the femur and tibia of a commercial broiler line. Poultry Science, v.81, p.1289-1294, 2002.

BAR, A.; SHINDER, D.; YOSEFI, S. et al. Metabolism and requirements for calcium and phosphorus in the fast-growing chicken as affected by age. British Journal of Nutrition, v.89, p.51-60, 2003.

BRUNO, L.D.G.; FURLAN, R.L.; MALHEIROS, E.B. et al. Influence of early quantitative food restriction on long bone growth at different environmental temperatures in broiler chickens. British Poultry Science, v.41, p.389-394, 2000.

CALDER, P.C. Immunoregulatory and anti-inflammatory effects of n-3 polyunsaturated fatty acids. Brazilian Journal of Medical and Biological Research, v.31, p.467-490, 1998.

CLAASSEN, N.; COETZER, H.; STEINMANN, C.M. et al. The effect of different n-6/n-3 essential fatty acid ratios on calcium balance and bone in rats. Prostaglandins, Leukotrienes and Essential Fatty Acids, v.53, p.13-19, 1995.

DUTRA JR., W.M.; ARIKI, J.; KRONKA, S.N. et al. Níveis do óleo de abatedouro avícola no desempenho e características da carcaça de frangos de corte. Revista da Sociedade Brasileira de Zootecnia, v.20, p.477-482, 1991. 
FRANCO, S.G. Programas de alimentação e fontes de óleo para frangos de corte. 1992. 118f. Tese (Doutorado em Zootecnia) - Faculdade de Ciências Agrárias e Veterinárias, Universidade Estadual Paulista, Jaboticabal, 1992.

FREEMAN, C.P. The digestion, absorption and transport of fats non-ruminants. In: WISEMAN, J. (Ed.). Fats in animal nutrition. London: Butterworths, 1984. p.105-122.

KRATZER, F.H.; VOHRA, P. [1996] The use of flaxseed as a poultry feedstuff. Disponível em: <http://animalscience.ucdavis. edu/avian/pfs21.htm>. Acesso em: 17/3/2005.

KRUEGER, M.C.; HORROBIN, D.F. Calcium metabolism, osteoporosis and essential fatty acids: a review. Progress in Lipid Research, v.36, n.2/3, p.131-151, 1997.

LEESON, S.; ZUBAIR, A.K. Digestion in Poultry I: Proteins and Fats. Disponível em: <http://www.novusint.com/Public/Library/ TechPaper.asp?ID=99>. Acesso em: 12/2/2006.

LETERRIER, C.; NYS, Y. Composition, cortical structure and mechanical properties of chicken tibiotarsi: effect of growth rate. British Poultry Science, v.33, p.925-939, 1992.

LIU, D.; DENBOW, D.M. Maternal dietary lipids modify composition of bone lipids and ex vivo prostaglandin $\mathrm{E}_{2}$ production in early postnatal Japanese quail. Poultry Science, v. 80, n.9, p.1344-1352, 2001.

LIU, D.; VEIT, H.P., WILSON, J.H. et al. Long-term supplementation of various dietary lipids alters bone mineral content, mechanical properties and histological characteristics of Japanese quail. Poultry Science, v.82, p.831-839, 2003.

MORAN JR., E.T.; TODD, M.C. Continuous submarginal phosphorus with broilers and the effect of preslaughter transportation: carcass defects, further-processing yields and tibia-femur integrity. Poultry Science, v.73, p.1448-1457, 1994

NELDER, J.A.; WEDDERBURN, W.M. Generalized linear models. Journal Royal Statistic Society, v.135, n.3, p.370-384, 1972.

NITSAN, Z.; DVORIN, A.; ZOREF, Z. et al. Effect of added soybean oil and dietary energy on metabolizable and net energy of broiler diets. British Poultry Science, v.38, n.1, p.101-106, 1997.

NOY, Y.; SKLAN, D. Digestion and absorption in the young chick. Poultry Science, v.74, p.366-373, 1995.

OVIEDO-RONDON E.O. Nutritional factors that affect leg problems in broilers. In: POULTRY NUTRITION CONFERENCE, 32., 2005, Raleigh. Proceedings... Raleigh: 2005. p. $58-88$

PUCCI, L.E.A.; RODRIGUES, P.B.; FREITAS, R.T.F. et al. Níveis de óleo e adição de complexo enzimático na ração de frangos de corte. Revista Brasileira de Zootecnia, v.32, n.4, p.909-917, 2003.

RATH, N.C.; BALOG, J.M.; HUFF, W.E. Comparative differences in the composition and biochemical properties of tibiae of seven- an seventy-two-week-old male and female broiler breeder chickens. Poultry Science, v.78, p.1232-1239, 1999.

RATH, N.C.; HUFF, G.R.; HUFF, W.E. et al. Factors regulating bone maturity and strength in poultry. Poultry Science, v.79, p.1024-1032, 2000.

REDDISH, J.M.; LILBURN, M.S. A comparison of growth and development patterns in diverse genotypes of broilers. 1. Male broilers growth. Poultry Science, v.83, p.1067-1071, 2004.
REICH, A.; JAFFE, N.; TONG, A. et al. Weight loading young chicks inhibits bone elongation and promotes growth plate ossification and vascularization. Journal of Applied Physiology, v.98, p.2381-2389, 2004.

REIS, D.T.C.; BARBOSA, A.A.; MORAES G.H.K. et al. Aspectos físicos, químicos e mecânicos de tíbias de frangos de corte machos e fêmeas. In: REUNIÃO ANUAL DA SOCIEDADE BRASILEIRA DE ZOOTECNIA, 42., 2005, Goiânia. Anais... Goiânia: Sociedade Brasileira de Zootecnia, [2005] (CD-ROM).

ROSTAGNO, H.S.; ALBINO, L.F.T.; DONZELE, J.L. et al. Tabelas brasileiras para aves e suínos: composição de alimentos e exigências nutricionais. 2.ed. Viçosa, MG: Editora UFV, 2005. $186 \mathrm{p}$.

RUTTEN, M.; LETERRIER, C.; CONSTANTIN, P. et al. Bone development and activity in chickens in response to reduced weight-load on legs. Animal Research, v. 51, p.327-336, 2002.

STATISTICAL ANALYSIS SYSTEM - SAS. SAS/STAT ${ }^{\circledR}$. User's guide: statistics. versão 8.1. 4.ed. Cary: SAS Institute, 2000. (CD-ROM).

SAKOMURA, N.; LONGO, F.A.; RABELLO, C.B. et al. Efeito do nível de energia metabolizável da dieta no desempenho e metabolismo energético de frangos de corte. Revista Brasileira de Zootecnia, v.33, n.6, p.1758-1767, 2004 (supl. 1).

SEEDOR, J.G.; QUARRUCCIO, H.A.; THOMPSON, D.D. The biophosphonate alendronate (MK-217) inhibits bone loss due to ovariectomy in rats. Journal of Bone and Mineral Research, v.6, p.339-346, 1991.

SKINNER, J.T.T.; WALDROUP, P.W. Allometric bone development in floor-reared broilers. Journal Applied Poultry Research, v.4, n.3, p.265-270, 1995.

TABEEIDIAN, A.; SADEGHI, G.H.; POURREZA, J. Effect of dietary protein levels and soybean oil supplementation on broilers performance. International Journal of Poultry Science, v.4, n.10, p.799-803, 2005.

WATKINS, B.A. [2000]. Role of lipids and phytochemicals in bone health. Disponível em: <http://www.ift.confex.com/ift/200/ techprogram/paper_4941.htm>. Acesso em: 10/10/2006.

WATKINS, B.A. [2003]. Longitudinal growth and modeling of bone. Disponível em: <http://www.novusint.com/Public/Library/ Techpaper.asp?ID=9ift.confex.com/ift/200/techprogram/ paper_4941.htm>. Acesso em: 12/2/2006.

WILLIAMS, B.; SOLOMON, S.; WADDINGTON, D. et al. Skeletal development in the meat-type chicken. British Poultry Science, v.41, p.141-149, 2000.

WILLIAMS, B.; WADDINGTON, D.; MURRAY, D.H. et al. Bone strength during growth: influence of growth rate on cortical porosity and mineralization. Calcified Tissue International, v.74, p.236-245, 2004.

YALCIN, S.; ÖZKAN, S.; COSKUNER, E. et al. Effects of strain, maternal age and sex on morphological characteristics and composition of tibial bone in broilers. British Poultry Science, v.42, n.2, p.184-190, 2001.

ZELENKA, J. Linseed oils with different fatty acid patterns in the diet of broiler chickens. Czech Journal of Animal, v.51, n.3, p.117-121, 2006. 